\title{
Nitroglycerin in Dermatology
}

\section{MIHAELA PAULA TOADER ${ }^{1,2}$, MADALINA MOCANU ${ }^{2,3 *}$, ROXANA IRINA IANCU ${ }^{3 *}$, STEFAN TOADER ${ }^{3}$, VIRGIL BULIMAR ${ }^{4}$, TATIANA TARANU ${ }^{1,2}$}

${ }^{1}$ University of Medicine and Pharmacy "Grigore T. Popa" Iasi, Faculty of Dental Medicine, Discipline of Oral Dermatology, 16 Universitatii Str., 700115, Iasi, Romania

${ }^{2}$ Clinical University Hospital of the Railways Sysytem, Dermatology Clinic, 1 Garabet Ibraileanu Str., 700506, Iasi, Romania

${ }^{3}$ University of Medicine and Pharmacy "Grigore T. Popa" Iasi, Faculty of Medicine, Discipline of Physiopathology, 16 Universitatii Str., 700115, Iasi, Romania

${ }^{4}$ University of Medicine and Pharmacy "Grigore T. Popa" Iasi, Faculty of Medicine, Discipline of General Surgery, 16 Universitatii Str., 700115, Iasi, Romania

\begin{abstract}
Nitroglycerin has traditionally been used in medicine for over 130 years for its potent dilator effect on both venous and arterial blood vessels. Cardiovascular ischemic diseases are among the classic indications. However, the possibility to incorporate nitroglycerin in different galenic forms renders it new therapeutic potential through topical application, both in surgery and in dermatology (Raynaud syndrome, chondrodermatitis, pernio erythema, alopecia areata, ulcers of different etiologies). Nitroglycerin is used for topical treatment as $0.5 \%, 1 \%$ or $2 \%$ ointment, lower concentrations limiting the probability of systemic adverse effects occurence.
\end{abstract}

Keywords: nitroglycerin, dermatology, vasodilation, analgesia

\section{Introduction}

Nitroglycerin is a chemical substance with explosive properties, initially synthetized in 1847 by the chemist Ascanio Sobrero and exploited for three decades in the ammunition industry [1]. It is obtained by esterification of cooled glycerin (to minimize unwanted effects of this strongly exothermic reaction) with concentrated nitric acid in the presence of sulfuric acid (Figure 1).

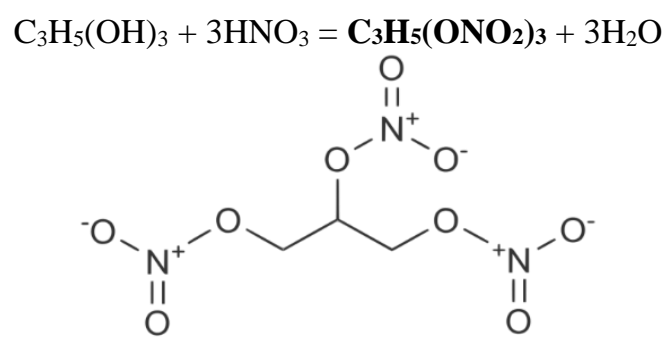

Figure 1. Nitroglycerin (trinitroglycerin, glycerin trinitrate, 1,2,3-trinitroxypropane) - chemical structure

Since 1878 nitroglycerin has been used in medicine in a diluted, non-explosive form, for its potent vasodilator effect on both arteries and veins. It is included by the World Health Organisation in the list of essential drugs, that comprises the most effective and safe medicines.

Cardiovascular ischemic morbid conditions (acute coronary syndrome, acute myocardial infarction, angina pectoris) are the main target of nitroglycerin therapy [2,3]. Topical nitroglycerin is indicated in dermatology (Raynaud syndrome, chondrodermatitis, ulcers, post-filler injection necrosis, alopecia areata, pernio erythema), surgery (anal fissures, hemoroids), orthopedics (tendinopathy), for treating several conditions with vasoconstriction as a common pathogenic mechanism [4-6].

*email: drmadalinamocanu@yahoo.com,rox_iancu@yahoo.com 
The chemical structure of glyceril trinitrate renders nitroglycerin the possibility to be incorporated in different pharmaceutical forms with either systemic effects (pills, solutions, sprays, patches) or local effects (creams). Absorbtion and duration of action onset are correlated with the pharmaceutical form, from 5 minutes in the case of sublingual pills to the delay effect of patches, which gives nitroglycerin superior bioavailability and multiple indications [7].

After absobtion, nitroglycerin (NTG) is degraded to nitric oxide under the action of the mitochondrial aldehyde-dehydrogenase (MAD). Nitric oxide (NO), the active metabolite, activates guanylate cyclase (GC) which induces an increase in the concentration of cyclic guanosine monophosphate (GMP) in smooth muscles and in other tissues. These events lead to dephosphorylation of myosin light chains which, in turn, induces smooth muscle relaxation and vasodilation (Figure 2). Even though this effect is predominant on venous blood vessels, it also noted in a dose-dependent manner on arterial blood vessels as well $[8,9]$.

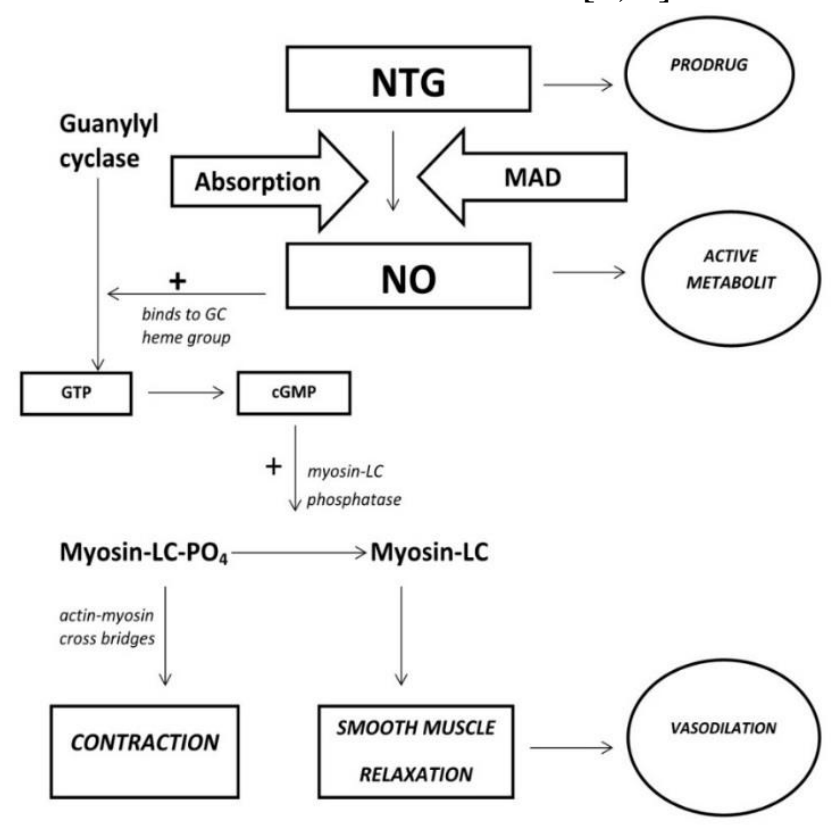

Figure 2. Nitroglycerin- biochemical mechanism of action

\section{Experimental part}

Nitroglycerin indications in dermatology are based on its vasodilator effect through topical application. Concentrations of $0.2 \%$, to $2 \%$ are utilized, according to the dimensions and location of the affected area, in order to minimize systemic absorbtion and to prevent adverse effects. Thus, concentrations of 0.5 and $1 \%$ are preferred for topical administration on the skin and $0.2 \%$ to $0.4 \%$ for rectal mucous membrane application, with proven efficacy and safety [10]. Adverse effects to topical nitroglycerin were only reported in a small number of cases, consisting mainly of local irritation. Rarely, headache appearing 2 hours after topical administration was reported.

Topical nitroglycerin is indicated in several dermatologic disorders with vasoconstriction as a common pathogenic mechanism, but with variable clinical manifestations, such as Raynaud syndrome, chondrodermatitis nodularis helicis, cutaneous ulcers, pernio erythema, alopecia areata, tissular necrosis after dermal filler injections [11, 12].

Our paper aims to review the main etiopathogenic and clinical aspects of several disorders that may benefit from topical nitroglycerin therapy and to analyze the mechanism responsible for its therapeutic effect. The clinical images are part of the archive of the Dermatology Clinic of the Clinical University Hospital of the Railways system in Iasi. The study was conducted in accordance with the bioethical norms of the European Union legislation. 


\section{Results and discussions}

Raynaud syndrome is a common vascular condition, with a prevalence of 5-10\% in the general population, characterized by recurrent digital arterial vasospasm, that manifests with episodes of colour changes from pale to cyanosis and hyperemia, paresthesia, burning sensation and throbbing pain (Figure 3). It may evolve to ischemia with digital ulcers, gangrene or other potentially invalidating complications that may require surgical treatment.

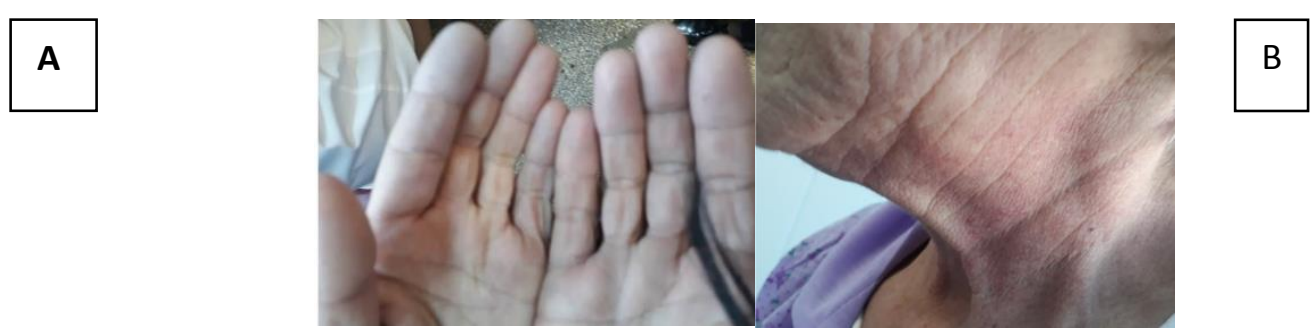

Figure 3. A. Raynaud syndrome - acral cyanosis and edema of the fingers; B. Scleroderma - indurated, sclerous plaque

Raynaud syndrome is classified into primary, also called Raynaud disease and secondary, also known as Raynaud phenomenon, associated to connective tissue autoimmune diseases, mainly scleroderma, mixed connective tissue disease or lupus erythematosus. While primary Raynaud syndrome is related to functional vascular aterations alone, in secondary Raynaud syndrome structural microvascular damage also occurs. Pathogenic mechanisms include an unbalance between vasodilatory and vasoconstrictor mediators, with increased levels of angiotensin II and decreased levels of nitric oxide, neural abnormalities with overactivity of $\alpha 2 \mathrm{c}$-adrenoreceptors and increased levels of neuropeptide $Y$ that contribute to vasoconstriction, as well as intravascular abnormalities with increased production of platelet thromboxane $\mathrm{A}_{2}$, a potent vasoconstrictor, as well as oxidative stress $[11,13,14]$.

Classic therapy includes systemic vasodilator drugs with moderate effects on symptoms such as pain [15]. Association with topical nitroglycerin proved efficacious by increasing local temperature with an average of $3^{\circ} \mathrm{C}$ after $3 \mathrm{~h}$ of topical application (patch or ointment with $2 \%$ nitroglycerin, reapplied every $6 \mathrm{~h}$ ), with constant maintenance of temperature for up to $12 \mathrm{~h}$. The main reported adverse effect was headache 2 hours after patch application [16].

Nitroglycerin targets both vasoconstriction and remodeling of the altered vascular endothelium in scleroderma, by increasing vascular elasticity. It acts in a similar way to 5-phosphodiesterase inhibitors by increasing GMP which induces vasodilation and smooth muscle relaxation. The active metabolite, nitric oxide, increases the local oxygen influx, thus improving symptoms in Raynaud syndrome.

Chondrodermatitis nodularis helicis is a benign dermatologic condition affecting the skin of the helix and antehelix, predominantly in male patients (M/F-10/1). It manifests as nodular, indurated, extremely painful lesions due to dermal and chondral ischemia generated by thinning of perichondral arteriols (Figure 4), leading to altered quality of sleep [17, 18].
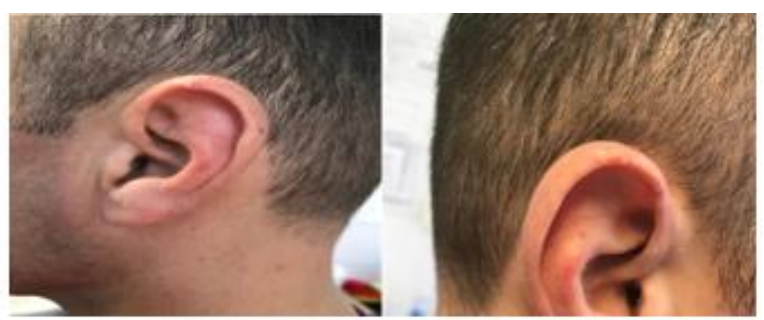

Figure 4. Nodular, indurated lesions on the helix and antehelix - chondrodermatitis nodularis helicis 
Therapeutic options with proven efficacy include minimally invasive methods such as intralesional cortisone or collagen injections, cryotherapy, or invasive methods such as electrodessication or surgical removal, with potential irreversible esthetic impairment [19]. Topical nitroglycerin, a noninvasive, safe and efficient method, is indicated due to both its vasodilator and antalgic effect. Nitroglycerin $2 \%$ ointment is recommended twice daily for three to four weeks until complete resolution. In case headache occurs the concentration is reduced to $1 \%$ [20].

Nitroglycerin beneficial effects are due to its ability to induce relaxation of arteriolar muscle fibers leading to a restored local blood flow and a decrease in local edema. Nitroglycerin also has an antalgic effect by central and peripheral nervous system pain modulation, leading to an improved quality of life and avoidance of invasive treatment methods.

Trophic ulcers are defined as deep dermal-hypodermal losses of substance, affecting mainly the lower extremities, in an area altered by disease, vascular or neural impairment, caused by an external factor and with no tendency to heal spontaneously $[3,8]$. They manifest as deep crateriform ulcers with variable shapes, sizes and colour (Figure 5).

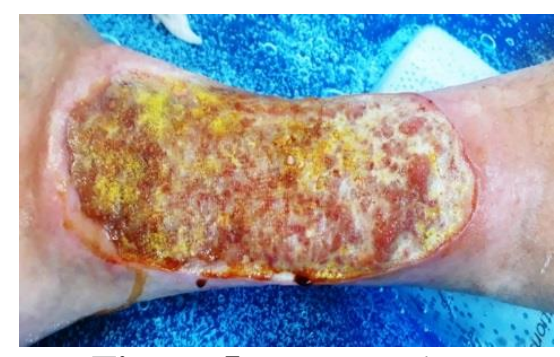

Figure 5. Venous ulcer

According to etiopathogeny, trophic ulcers are classified into two main cathegories: vascular and non-vascular. The vast majority $(95 \%)$ are due to vascular impairment, either venous (venous insufficiency, venous thrombosis) in $70 \%$ of the cases, or arterial (chronic obliterant artheriopathy, obliterant thrombangeitis, acute arterial occlusion) in 30\% of the cases. $15-20 \%$ of the trophic ulcers due to vascular causes are the result of mixed arterial and venous impairment. The non-vascular trophic ulcers account for the rest of 5\% and may have several causes: infectious, neuropathic, hematologic, traumatic [21].

Venous ulcer is the most severe complication of venous insufficiency, with a prevalence of $1.69 \%$ in patients aged over 65 years. Raffetto et al. considered venous ulcers the consequence of high venous pressure on dermal microvasculature (22). Therapy of venous ulcers includes: chronic systemic treatment with vasodilators, antithrombotic drugs, venotrophic medication, local treatment (debridement, cleaning, wound dressings), surgical intervention in selected cases, avoidance of prolonged standing, treatment of high blood pressure, cessation of smoking, compression therapy [23].

Topical nitroglycerin stimulates vasodilation which decreases venous pressure and restores local blood flow leading to adequate tissue oxygenation required for tissue regeneration. According to ulcer size concentrations of $1 \%$ or $2 \%$ may be used.

In diabetic patients trophic ulcers have specific features in regard to etiopathogeny and evolution. Diabetic neuropathy favors trauma and ulcerations in the lower legs, both by posture anomalies with increased pressure on the feet and by decreased sensitivity to pain, temperature and pressure, increasing the risk of injury [24]. Clinical manifestations include xerosis, fissures and ulcers (Figure $6)$.

Ischemia leads to a delay in wound healing by decreased blood flow and reduced tissular oxygenation [25]. Topical nitroglycerin therapeutic effects are due to increasing GMP and nitric oxide resulting in local vasodilation and increased oxygen which accelerates the elimination of catabolites and reduces pain, pruritus and inflammation. 


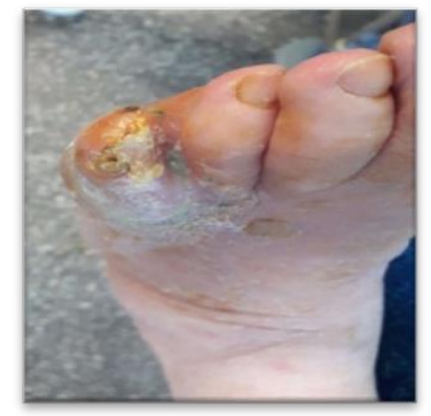

Figure 6. Interdigital

ulcer in a diabetic

patient

Alopecia areata is considered a T-cell mediated autoimmune disease characterized by recurrent non-scarring hair loss that may affect all hair-bearing areas. It manifests with smooth, slightly erythematous or normal coloured, round to oval alopecic patches that may contain several pathognomonic exclamation point hairs (Figure 7). Most patients are asymptomatic. However some may experience discomfort or a burning sensation [26].

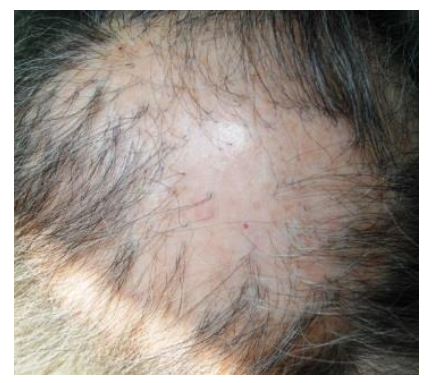

Figure 7. Alopecia areata with exclamation point hairs at the periphery of the alopecic patch

Pathophysiology of alopecia areata is not yet completely understood. Autoimmunity in genetically predisposed individuals, cytokines inhibiting hair growth such as interleukin 1 and tumor necrosis factor, viral etiology and changes in the local innervation and vasculature with decreased levels of calcitonin gene-related peptide were hypothesized.

Treatment options include potent topical corticosteroids, minoxidil solution, topical dithranol, topical nitroglycerin, intralesional corticosteroids [27]. Topical nitroglycerin may counteract the effect of decreased levels of calcitonin gene-related peptide. Also, by inducing vasodilation, it favors the afflux of nutritional substances, as well as the absorbtion of therapeutic substances concomitantly administered.

Tissue necrosis related to dermal filler injection is a rare, but potentially serious adverse reaction due to vascular compromise through mainly two mechanisms: either direct intravascular injection of the filler with vascular occlusion, or compression of the adjacent vasculature by the injected material, when its volume exceeds the pressure of the arteriole perfusing the area. Symptoms of arterial occlusion include immediate or early white discoloration of the skin and severe pain. Venous impairment manifests with delayed dull pain and dark discoloration. Treatment includes massage of the affected area, warm compresses, hyperbaric oxygen in cases of impending massive skin necrosis. Injection of hyaluronidase may be attempted if a hyaluronic acid dermal filler was used. Nitroglycerin $2 \%$ paste is recommended in order to promote vasodilation and to facilitate blood flow to the affected area (28).

\section{Conclusions}

Nitroglycerin is a substance with multiple therapeutic indications, superior bioavailability and optimal safety profile. The possibility to incorporate nitroglycerin in pharmaceutical forms suitable for topical administration renders it new indications in dermatology, surgery and orthopedics. In dermatology, nitroglycerin may be used as monotherapy or in combination with other therapies for its vasodilator, anti-inflammatory and antalgic properties. 


\section{References}

1.Di CARLO, F. J., Nitroglycerin Revisited: Chemistry, Biochemistry, Interactions, Drug Metabolism Reviews, 4, no. 1, 1975, p. 1-38.

2.CHEN, Z., FOSTER, M.W., ZHANG, J., MAO, L., ROCKMAN, H.A., KAWAMOTO, T. et al. An essential role for mitochondrial aldehyde dehydrogenase in nitroglycerin bioactivation, Proceedings of the National Academy of Sciences, 102, no. 34, 2005, p. 12159-1216.

3.LUPESCU, G., LUPESCU, R., PLAVAT, C., COLLADO, A.L., The Local Effects of Transdermal Nitroglycerine Treatment in Peripheral Vascular Pathology and in Various Other Diseases, J Clin Basic Cardiol, 4, 2001, p. 295-296.

4.KATZUNG, B.G., Section III Cardiovascular-renal Drugs, Basic and clinical pharmacology, 10th ed. San Francisco: McGraw Hill, 2007, p.

183-90.

5. EPHRAIM D GAMBITO, CONSUELO B. GONZALEZ-SUAREZ, TERESA I OQUIÑENA, Ricardo B Agbayani, Evidence on the Effectiveness of Topical Nitroglycerin in the Treatment of Tendinopathies: A Systematic Review and Meta-Analysis Arch Phys Med Rehabil, 91, 2010, p. 1291 1305.

6.RATNASINGHAM, K, UZZAMAN, M., ANDREANI, S.M.,LIGHT, D., PATEL, B., Meta-analysis of the Use of Glyceryl Trinitrate Ointment After Haemorrhoidectomy as an Analgesic and in Promoting Wound Healing, Int J Surg, 8, no. 8, 2010, p. 606-611.

7.CRISTEA, A.N., Tratat de Farmacologie, cap. V Farmacologia aparatului cardiovascular, subcap. 3.2.6 Antianginoase. Nitroglicerina, Ed. Medicală, București, 2006, p. 418-419.

8.MOSALLI, R., ELBAZ, M., PAES, B., Topical Nitroglycerine for Neonatal Arterial Associated Peripheral Ischemia following Cannulation: A Case Report and Comprehensive Literature Review, Case Reports in Pediatrics, 2013, p. 1-7.

9.FURNICA, C., CHISTOL, R.O., LEON CONSTANTIN, M.M., ALEXA, A.I., TINICA, G., Calcification of Bioprosthetic Heart Valves Biochemical substrate and prevention, Rev. Chim., 66(10), 2015, 1716-1719.

10.SCHOLEFIELD, H., BOCK, J.U., MARLA, B., RICHTER, H.J., et al., A dose finding study with $0.1 \%, 0.2 \%$, and $0.4 \%$ glyceryl trinitrate ointment in patients with chronic anal fissures, Gut, 52, 2003, p. 264-269.

11.CURTISS, P., SCHWAGER, B.A., COBOS, G., SICCO, K., et al., A systematic review and metaanalysis of the effects of topical nitrates in the treatment of primary and secondary Raynaud's phenomenon, J Am Acad Dermatol, 78, no. 6, 2018, p. 1111-1118.

12.FLYNN, V., CHISHOLM, C., GRIMWOOD, R., Topical nitroglycerin: A promising treatment option for chondrodermatitis nodularis helicis. J Am Acad Dermatol, 65, no. 3, 2011, p. 531536.

13.PRETE, M., FATONE, M.C., FAVOINO, E., PEROSA, F., Raynaud's phenomenon: from molecular pathogenesis to therapy. Autoimmunity Reviews, 13, 2014, p. 655-667.

14.POPE, J.E., The Diagnosis and Treatment of Raynaud's Phenomenon, Drugs, 67, 2007, p. 517525.

15.CSIKI, Z., GARAI, I., SHEMIRANI, A.H., PAPP, G., ZSORI K.S., et al., The effect of metoprolol alone and combined metoprolol-felodipin on the digital microcirculation of patients with primary Raynaud's syndrome, MicrovascRes, 82, 2011,

p. 84-87.

16.KAN, C., AKIMOTO, S., ABE, M., OKADA, K., ISHIKAWA, O., Preliminary thermographic evaluation of new nitroglycerine tape on the peripheral circulatory disturbance in systemic sclerosis. Ann Rheum Dis, 61, 2002, p.

177-179.

17.CHAN, H.P., NEUHAUS, I.M., MAIBACH, H.I., Chondrodermatitis nodularis chronica helicis in monozygotic twins. Clin Exp Dermatol, 34, 2008, p. 358-359. 
18.AVITIA, S., HAMILTON, J.S., OSBORNE, R.F., Epithelial-myo-epithelial carcinoma, Ear Nose Throat J, 84, 2005, p. 764-767.

19.RAJAN, N., LANGTRY, J.A.A., The punch and graft technique: a novel method of surgical treatment for chondrodermatitis nodularis helicis, Br J Dermatol, 157, 2007, p. 744-747.

20.FLYNN, V., CHISHOLM, C., GRIMWOOD, R., Topical nitroglycerin: A promising treatment option for chondrodermatitis nodularis helicis J Am Acad Dermatol, 65, 2011, 531-536.

21.SHRINIVAS, G., AMOL, W., Study of the pathogenesis and diagnosis of ulcer of lower extremity under various conditions Int J Res Med Sci., 4, no.2, 2016, p. 621-627.

22.RAFFETTO, J.D., MAERSTON, W.A., Venous ulcer: what is new?, Plast Reconstr Surg., 127, Suppl 1, 2011, p. 279S-288S.

23.COLlinS, R., SERAJ, S., Diagnosis and Treatment of Venous Ulcers, Am Fam Physician., 81, 2010, p. 989-996.

24.HUGHES, M., MOORE, T., MANNING, J., WILKINSONC, J., et al. Reduced perfusion in systemic sclerosis digital ulcers (both fingertip and extensor) can be increased by topical application of glyceryl trinitrate, Microvascular Research, 111, 2017, p. 32-36.

25.PETROVICI, C., DOROBĂȚ, C.M., BEJAN, C.C., JUGĂNARIU, G., SIMIRAȘ, E., FILIP, O., LUCA, V., MIFTODE, E.G., CERCETĂRI CLINICO-EPIDEMIOLOGICE RETROSPECTIVE ASUPRA INFECŢIILOR INVAZIVE LA BOLNAVII DIABETICI ÎN SPITALUL CLINIC DE BOLI INFECŢIOASE IAŞI, ÎN PERIOADA 2008-2010 Rev Med Chir, 115, no.4, 2011, p.1035-1041.

26.LAUREN, C., STRAZZULLA, B.A., CHUN WANG, E.H., AVILA, L., et al., Alopecia areata: An appraisal of new treatment approaches and overview of current therapies J Am Acad Dermatol, 78, 2018, p. 15-24.

27.CHANG, K.H., ROJHIRUNSAKOOL, S., GOLDBERG, L.J., Treatment of severe alopecia areata with intralesional steroid injections. J Drugs Dermatol., 8, 2009, p.909-912.

28.URDIALES-GALVEZ, F., DELGADO, N.E., FIGUEIREDO, V. et al., Treatment of Soft Tissue Filler Complications: Expert Consensus Recommendations, Aesth Plast Surg 42, 2018, p. 498-510.

Manuscript received: 16.01 .2020 